\title{
3 Demographic effects of large, introduced herbivores 4 on a long-lived endemic plant
}

\author{
5 Pisanu Stefania - Farris Emmanuele • \\ 6 Filigheddu Rossella • García Maria Begoña
}

Abstract The introduction of alien ungulates is a major threat for the survival of endangered plants, especially in island ecosystems. However, very few studies have investigated the potential damage of large herbivores on plant diversity in Mediterranean protected areas. In this study, we describe the population structure and the long-term dynamics of the main populations of the Sardinian narrow endemic Centaurea horrida Bad. (Asteraceae), by means of permanent plots where individual plants were tagged and monitored through 6 years (2004-2009). We monitored this endangered plant at three sites: two were protected areas where introduced and feral ungulates are present, and the other one was a non-protected site without introduced

Electronic supplementary material The online version of this article (doi:10.1007/s11258-012-0110-9) contains supplementary material, which is available to authorized users.

P. Stefania $(\bowtie) \cdot$ F. Emmanuele $\cdot$ F. Rossella

Dipartimento di Scienze della Natura e del Territorio,

Università degli Studi di Sassari, Via Piandanna 4, 07100

Sassari, Italy

e-mail: pisanus@uniss.it

F. Emmanuele

e-mail: emfa@uniss.it

F. Rossella

e-mail: filighed@uniss.it

G. M. Begoña

Instituto Pirenaico de Ecología (CSIC), Apdo 13034,

50080 Zaragoza, Spain

e-mail: mariab@ipe.csic.es ungulates. We found that adults and saplings were more 23 abundant at the non-protected site. Through matrix models, we also highlighted that the non-protected population showed the highest population growth rate. Finally, by means of an exclusion experiment for ungulates at one protected site, we demonstrated that herbivores had a negative effect on the survival of seedlings and adult plants, and reduced the stochastic population growth rate. An LTRE analysis showed that differences in the survival, especially of adult individuals, had the highest responsibility in explaining the higher population growth rate when herbivores are excluded. Our study constitutes a clear example on how the protection of alien large herbivores can have opposite effects on the conservation of an endangered plant. Some management options are proposed, and the urgent need of manipulative experiments on speciesspecific interactions between protected plants and alien herbivore species is invoked.

Keywords Centaurea horrida Bad., demography · LTRE - Mediterranean - Stochastic matrix models . Ungulates introduction

\section{Introduction}

Herbivory is one of the most dominant biotic interactions in nature. Plants form the basal resource of virtually all food webs, and herbivores consume $10-15 \%$ of the plant biomass produced annually in

\begin{tabular}{|l|lll|}
\hline Journal : Medium 11258 & Dispatch : 16-8-2012 & Pages : 11 \\
Article No. : $\mathbf{1 1 0}$ & $\square$ LE & $\square$ TYPESET \\
& MS Code : VEGE3349 & $\checkmark \mathrm{CP}$ & $\checkmark$ DISK \\
\hline
\end{tabular}


both natural and managed ecosystems (Cyr and Pace 1993). Herbivory effects on plant performance have been widely recognized, both at the individual and population level (Ehrlén 2002; Hawkes and Sullivan 2001; Maron and Crone 2006; Jenkins et al. 2007). Interactions among plants and herbivores are increasingly men-mediated in many biogeographical areas by means of both shepherding activities (Farris and Filigheddu 2008) and/or ungulates introduction (Dolman and Waber 2008). Actually, introduced ungulates and feral domestic animals may constitute one of the major threats to plant biodiversity (Spear and Chown 2009), in particular in insular ecosystems (Courchamp et al. 2003). Island ecosystems (Whittaker and Fernández-Palacios 2007), and particularly the Mediterranean ones (Thompson 2005), are considered among the most fragile from an ecological point of view. Given the strong impacts of introduced ungulates on vegetation structure and composition, and soil system functioning (see for example Farris et al. 2010) extensive controls of the introduced herbivores seem to be necessary, especially in islands (Garzón-Machado et al. 2010).

Tyrrhenian islands (Balearic Archipelago, Corsica, Sardinia and Sicily) are one of the Mediterranean biodiversity hotspots (Médail and Quézel 1997, 1999; Myers et al. 2000). Sardinia, for example, shows a rough estimate of about 2,500 vascular plants (Conti et al. 2005), of which $6.2 \%$ are exclusive to the island and are in need of conservation actions due to their extinction risk (Pisanu et al. 2009; Fenu et al. 2011, 2012). A large fraction of endemic plants (42.3\%) grow in coastal, halophytic, and rocky habitats (Bacchetta et al. 2012), often on harsh areas like many Mediterranean endemics (Lavergne et al. 2004). Although western Mediterranean islands had a variety of endemic large herbivores due to migratory events during the entire Cenozoic (Palombo 2009), the island fauna is almost exclusively characterized by continental generalist mammals nowadays (Masseti 2009). As a consequence, the local flora of these islands is now suffering the impact of this foreign interaction.

In the last decades, the introduction of different kinds of alien ungulates took place both for hunting purpose in some areas (i.e., mouflon on the Asinara islet, Sardinia), and for conservation purposes in many other areas like protected spaces. The effect of alien herbivores (ungulates) in Mediterranean protected areas has not been evaluated at a large scale (Courchamp et al. 2003), and very few studies have shown the potential damage on overall diversity or particular plant species.

In this paper, we focus on the demography of the Mediterranean narrow endemic Centaurea horrida Bad. (Asteraceae), a perennial, sea-cliff plant restricted to the North of Sardinia. Over 6 years, we individually monitored hundreds of plants in three out of the five populations this species occurs, located in two protected and one non-protected areas. In protected areas, ungulates (wild boar, deer and mouflon) have been introduced in the last decades, and constitute now an important component of the ecosystems. Furthermore, domestic ungulates (goats, horses and donkeys) have become feral. Experiments to establish herbivores control and open habitats maintenance for the conservation of $C$. horrida populations have been recently invoked (Farris et al. 2012).

We first describe the current population structure, the frequency of damage at each place, and the longterm population dynamics through matrix models. Then, we evaluate how herbivores affect multiple demographic vital rates into a population-projection model (Farrington et al. 2009; Abe et al. 2008; Knight et al. 2009; McEachern et al. 2009; García et al. 2010), comparing the long-term dynamics of plants in/out two large mammal exclusions. Finally, we disentangled which vital rates and plant stages had the largest responsibility on differences between stochastic population growth rates of plants in/out exclusions.

The following specific questions were addressed: (1) Does the demographic structure of $C$. horrida populations in protected and non-protected areas differ? (2) Do populations differ in their current stochastic population growth rate? (3) To what extent are herbivores a threat for the future of this species? Results will be discussed with the aim to clarify which of the different current management regimes (aprotected space with introduced ungulates; $b-$ protection from ungulates by fencing; and $\mathrm{c}-$ nonprotected space without ungulates) seems to be better for the persistence of this endangered plant.

\section{Materials and methods}

Study species

The genus Centaurea L. (Asteraceae) includes 143 roughly 400 species (Susanna and Garcia-Jacas

$\begin{array}{lll}\text { Journal : Medium 11258 } & \text { Dispatch : 16-8-2012 } & \text { Pages : 11 } \\ \text { Article No. : } \mathbf{1 1 0} & \square \text { LE } & \square \text { TYPESET } \\ \text { MS Code : VEGE3349 } & \checkmark \text { CP } & \checkmark \text { DISK }\end{array}$


2009), with many narrow endemics (Kose et al. 2010; Kultur 2010; López-Alvarado et al. 2011). Centaurea horrida is endemic of the North of Sardinia (Italy). It is protected by the Berne Convention, listed with priority status in Annexe II of the EU "Habitat" Directive, and considered endangered (EN) on the basis of IUCN criteria. This cushion-forming spiny dwarf plant is self-incompatible and reproduces mainly sexually by means of cross-pollination carried out by insects. The capitula usually flower in the late spring (April-May) and seeds are released in July-August. Seeds have an elaiosome attractive for ants, and seedlings are usually located near the mother plant (Pisanu et al. 2009).

Study sites

Centaurea horrida is restricted to five populations on sea-cliffs, along the coasts of Northern Sardinia, where it grows in both cliff face and cliff plateau (see map in Farris et al. 2012). Because two of the five populations, Piana and Tavolara Islets, are small (87 and 175 individuals respectively), this demographic study was conducted in the other three populations, located in Alghero (AHO), Asinara (ASI) and Stintino (STI; Table 1). We believe that environmental conditions and genetic differences among sites are not so high except for herbivores density.

In fact, the bioclimate is always Thermomediterranean dry euoceanic type, and the vegetation is also very similar in the three sites (see Table 38 in Biondi et al. 2001). ASI and STI have the same geological substrate (schist) and AHO is limestone. On the other hand, although all populations showed moderate levels of genetic differentiation, one of the five populations $(\mathrm{AHO})$ was more strongly differentiated from the other four, suggesting certain barrier to regular gene exchange (Mameli et al. 2008).

All the three sites are included in the Natura 2000 network, but in Sardinia this does not mean effective protection or specific management. For a land to receive an active management, it is necessary to be included within a protected area as a National or Regional Park, or a Marine Protected Area. This is the case of ASI and AHO, located in the National Park of Asinara, established in 1997, and the Regional Park of Porto Conte, established in 1999, respectively.

Between 1990 and 2010, a total density of 0.24 ungulates ha ${ }^{-1}$ was recorded at AHO: $42 \%$ were deer, $31 \%$ wild boars (they were already present at this site), $17 \%$ feral donkeys, and $10 \%$ feral horses. Roughly, the population of each species increased around 30-40\% every 10 years. At ASI, in the same period, 300 donkeys, 1,000 wild boars, 600 mouflons, 180 horses, and 7,000 feral goats were present on the island $(5,200 \mathrm{ha})$. This means that at ASI the total density of herbivores reached 1.7 individuals $\mathrm{ha}^{-1}$ because the ungulates do not have natural predators here, and hunting them is forbidden. No ungulates are present at STI, except wild boars.

All the ungulates, except wild boars at AHO and STI, were introduced few decades ago (before the parks institution) for hunting purpose (ASI) or for reintroduction (deer at $\mathrm{AHO}$ ), or simply were domestic animals that became feral (goats, donkeys, horses). Only recently some eradication programmes (carried out with the use of harmless traps) have been started to

Table 1 Characteristics of the study sites

\begin{tabular}{|c|c|c|c|}
\hline Population & Asinara & Stintino & Alghero \\
\hline Code & ASI & STI & $\mathrm{AHO}$ \\
\hline Coordinates & $41^{\circ} 00^{\prime} \mathrm{N}-8^{\circ} 12^{\prime} \mathrm{E}$ & $40^{\circ} 56^{\prime} \mathrm{N}-8^{\circ} 11^{\prime} \mathrm{E}$ & $40^{\circ} 36^{\prime} \mathrm{N}-8^{\circ} 08^{\prime} \mathrm{E}$ \\
\hline Geology & Schist & Schist & Limestone \\
\hline Bioclimate & $\begin{array}{l}\text { Thermomediterranean dry } \\
\text { euoceanic }\end{array}$ & $\begin{array}{l}\text { Thermomediterranean dry } \\
\text { euoceanic }\end{array}$ & $\begin{array}{l}\text { Thermomediterranean dry } \\
\text { euoceanic }\end{array}$ \\
\hline $\begin{array}{l}\text { Inclusion in the } \\
\text { Natura } 2000 \text { network }\end{array}$ & ITB010001 & ITB010043 & ITB010042 \\
\hline Effective management & Asinara National Park & None & Porto Conte Regional Park \\
\hline $\begin{array}{l}\text { Ungulates introduced in the last } \\
\text { century }\end{array}$ & $\begin{array}{l}\text { Donkeys, horses, goats, mouflon, } \\
\text { wild boars }\end{array}$ & None & Deer, donkeys, horses \\
\hline Other ungulates & None & Wild boars & Wild boars \\
\hline
\end{tabular}

\begin{tabular}{|l|lll|}
\hline & Journal : Medium 11258 & Dispatch : 16-8-2012 & Pages : 11 \\
Article No. : $\mathbf{1 1 0}$ & $\square$ LE & $\square$ TYPESET \\
& MS Code : VEGE3349 & $\checkmark \mathrm{CP}$ & $\checkmark$ DISK \\
\hline
\end{tabular}


decrease feral goats and wild boars at ASI: from 2007 to 2011 wild boars diminished to 300 and goats to 3,000 .

\section{Sampling demographic data}

In order to answer question one, four $10 \times 10 \mathrm{~m}^{2}$ permanent plots were established at each site of study in June 2004, and all the individuals of $C$. horrida within plots were mapped, tagged, and monitored yearly until 2009. We classified individuals of C. horrida in three life stages: 1) seedlings (sdl), still with cotyledons (often with one or two pairs of leaves but without stalks); 2) saplings (sap), non-reproductive individuals, usually less than $30 \mathrm{~cm}$ of diameter); and 3) adults, all reproductive individuals. Adults were further assigned to three size-classes depending on maximum diameter: $\mathrm{R} 1(\varnothing<30 \mathrm{~cm})$; R2 $(31 \mathrm{~cm}$ $<\varnothing<70 \mathrm{~cm})$, and R3 $(\varnothing>70 \mathrm{~cm})$.

Over the 6 years of monitoring, each individual was recorded as alive or dead, sapling, or adult, and the maximum diameter of the cushion measured with a calliper. Fecundity was calculated as the total seed production, from the total number of capitula (estimated using a grid on the bush surface), and counting capitula in four quadrats and the average number of fertile achenes per capitulum (estimated by collecting at random 3 capitula from each adult plant). All the seedlings found in the annual census after careful inspection within plots were considered as new recruits.

Because our research was limited by population availability and population sizes (a common situation for endangered plant species), site was used as a fixed factor in comparative analyses carried out among specific populations investigated. Two-ways ANOVAs were used to test differences in the relative proportions of each stage of $C$. horrida individuals among sites, and to test differences in seeds production among sites and among adult classes.

For all the ANOVAs performed, the homogeneity of variances was tested a priori using Cochran's $C$-test, and data were appropriately transformed, if necessary. Whenever transformation did not produce homogeneous variances, ANOVA was applied after setting $\alpha=0.01$ to compensate for the increased likelihood of Type I errors (Underwood 1997). Student-NewmanKeuls (SNK) tests were carried out to compare the mean values of all significant factors (Underwood
1997). ANOVAs were conducted using the GMAV5 software package (University of Sydney).

Matrix parameterization

In order to answer question two, stage-based population-projection matrix models were used to explore the dynamics of populations under current conditions. Each plant was included in one of the five stages above mentioned (sd1, sap, R1, R2, R3), and transition rates between pairs of classes were calculated for each pair of consecutive years.

Since experiments in the green house demonstrated that seeds germinate mostly within the year after being released (Pisanu unpublished), fertility of each class was set as the proportional part of seedlings in $t+1$, relative to the mean number of seeds released by plants in each class in $t$ (anonymous reproduction, Caswell 2001). A total of 15 annual Lefkovitch projection matrices were set for each combination of site (AHO, ASI, STI) and consecutive years (2004-2005, 2005-2006, 2006-2007, 2007-2008, 2008-2009). They were constructed according to the standard procedure of transition probabilities of the life cycle graph (Caswell 2001), from estimates of fertility and transition probabilities among stage classes.

Projection matrices were the basis for linear timeinvariant matrix models of the form $n_{t+1}=A * n_{t}$ (Caswell 2001), where $n_{t+1}$ is a vector with the abundances of stages in the population at time $t$, and $A$ integrates all the probabilities $\left(a_{i j}\right)$ for an average individual plant in class $j$ at a moment $t$, to be in class $i$ after one year. The dominant eigenvalue $(\lambda)$ of the projection matrix represents the deterministic population growth of the species at a particular site and time. To construct $95 \%$ confidence intervals for the projected population growth rates, bootstrapping was applied by resampling 2,000 times the observed fates of monitored plants. The bias-corrected percentile method provided the lower and upper bounds (see e.g., McPeek and Kalisz 1993; Caswell 2001). The stochastic growth rate $\left(\lambda_{\mathrm{s}}\right)$ and an approximate $95 \%$ Confidence Interval (CI) was calculated for each population by simulation of 50,000 population growth increments, considering that each matrix had the same probability of occurrence. The arithmetic mean and variance of $\log \left(N_{t+1} / N_{t}\right)$ over all pairs of adjacent years was calculated using the Stoch_log_lam routine of Morris and Doak (2002).

\begin{tabular}{|l|lll|}
\hline & Journal : Medium 11258 & Dispatch : 16-8-2012 & Pages : $\mathbf{1 1}$ \\
Article No. : $\mathbf{1 1 0}$ & $\square$ LE & $\square$ TYPESET \\
& MS Code : VEGE3349 & $\checkmark \mathrm{CP}$ & $\checkmark$ DISK \\
\hline
\end{tabular}



across years.
In order to answer question three, we first evaluated the occurrence of damage on $C$. horrida populations: in 2006, we randomly established four $2 \times 20 \mathrm{~m}^{2}$ transects at each site of study. Each plant included in transects was assigned to one of the above-mentioned stages, and to one of the following categories of injury: (1) mechanical damage (MD, damage mainly caused by trampling of horses, donkeys, deers, wild boars, and goats); (2) browsing (BR); (3) unthreading (UN, breaking of single branches caused by deers and goats: this differs from browsing because the last implies only a surface damage on the cushion plants; whereas the unthreading means damage of a single branch that is cut from the internal part of the plant); and (4) no damage (ND). Differences in the frequency of damaged plants among populations and classes were tested by Generalized Linear Models (GLM; glm procedure with logit link function; R statistical software version 2.11.1; R Development Core Team 2010).

Second, we tested the overall effect of herbivores on $C$. horrida performance using a demographic approach based on exclosures to ungulates at site ASI. Two $10 \times 10 \mathrm{~m}^{2}$ plots were fenced in December 2005 (thereafter "fenced plots"), and two open $10 \times 10 \mathrm{~m}^{2}$ control plots were established nearby (thereafter "control plots"). All plants in the four plots were monitored as in permanent plots.

Two-way ANOVA was used to test differences in seed production between treatments (Fenced vs Control) and adult size classes. Generalized Linear Models (GLM; glm procedure with logit link function; R statistical software version 2.11.1; R Development Core Team 2010) were used to test the effect of "fencing" on the survival of seedlings, saplings, and adult plants, after pooling all the transition events

The long-term effect of herbivores was evaluated by matrix models, and a total of 6 annual Lefkovitch projection matrices were constructed from this exclusion experiment: one for each combination of treatment and year (control vs fenced, 2006-2007, 2007-2008, 2008-2009). The stochastic growth rate $\left(\lambda_{\mathrm{s}}\right)$ and an approximate $95 \%$ Confidence Interval (CI) were calculated for each treatment following the same procedure described above. In order to quantify the contribution of each matrix element $\left(a_{i j}\right)$ to the observed variation in $\lambda$ between fenced and control plots (overall effect of herbivores), we used a one-way life table response experiment analysis (LTRE, Caswell 2001). This analysis takes into account differences in the values between pairs of the same matrix element (each one provided by the average matrix of each treatment), and its sensitivity evaluated at the average matrix.

\section{Results}

Population structure

There were no significant differences between the three sites in the relative proportion of individuals in each stage $\left(F_{2,8}=8.84, P=0.9991\right)$. Adults were the prevalent life stage in all three sites and during all the period of study $\left(F_{2,8}=15.88, P<0.0001\right)$ : on average, the density of seedlings was $3.8 \pm 0.47$ individuals $100 \mathrm{~m}^{-2}$, saplings were $12.9 \pm 1.84$ individuals $100 \mathrm{~m}^{-2}$, R1 adults reached an average density of $16.5 \pm 2.65$ individuals $100 \mathrm{~m}^{-2}, \mathrm{R} 2$ were $25.2 \pm$ 3.33 individuals $100 \mathrm{~m}^{-2}$, and $\mathrm{R} 3$ had a density of $19.8 \pm 2.37$ individuals $100 \mathrm{~m}^{-2}$. On average STI showed densities 2-3 times higher than AHO and ASI. For the saplings, STI showed double density in comparison to the other two sites, whereas seedling variability among sites was very low (Fig. 1).

The differences in seed production were highly significant among adult classes: R1 produced on average $65.6 \pm 6.23$ seeds, R2 produced $627.1 \pm$ 53.13 , and $\mathrm{R} 3$ produced $2915.1 \pm 184.92$ seeds $\left(F_{2,4}=\right.$ 25.44, $P<0.0001$ ) (Fig. 2).

Population trends

None of the 15 yearly matrices produced deterministic lambdas significantly below one. On the contrary, some values were significantly above one (the CI did not intercept $\lambda=1$ ), indicating that some years some populations were growing up to a maximum of $2.4 \%$ (AHO 2005-2006; Fig. 3). Temporal variability of deterministic lambdas was larger in $\mathrm{AHO}\left(\sigma^{2}=\right.$ 0.038) and lower in STI (0.016; see also Fig. 3). The stochastic population growth showed that populations were growing over the study period at a rate of $0.17 \%$ (AHO), $0.54 \%$ (ASI), and $1.12 \%$ (STI). Thus, STI showed the highest population growth rate and the less variable one through time.
381

382

383

384

385

386

387

388

389

390

391

392

393

\begin{tabular}{|l|lll|}
\hline & Journal : Medium 11258 & Dispatch : 16-8-2012 & Pages : 11 \\
Article No. : $\mathbf{1 1 0}$ & $\square \mathrm{LE}$ & $\square$ TYPESET \\
& MS Code : VEGE3349 & $\cup_{\mathrm{CP}}$ & $\searrow$ DISK \\
\hline
\end{tabular}


Fig. 1 Mean densities \pm SE (individuals $100 \mathrm{~m}^{-2}$; $N=4$ ) of seedlings, saplings, and adults of three size classes at three study sites monitored for 6 years

Fig. 2 Mean values ( \pm SE) of seeds per each adult class evaluated on all the individuals belonging to the three size classes at the three study sites monitored for 6 years
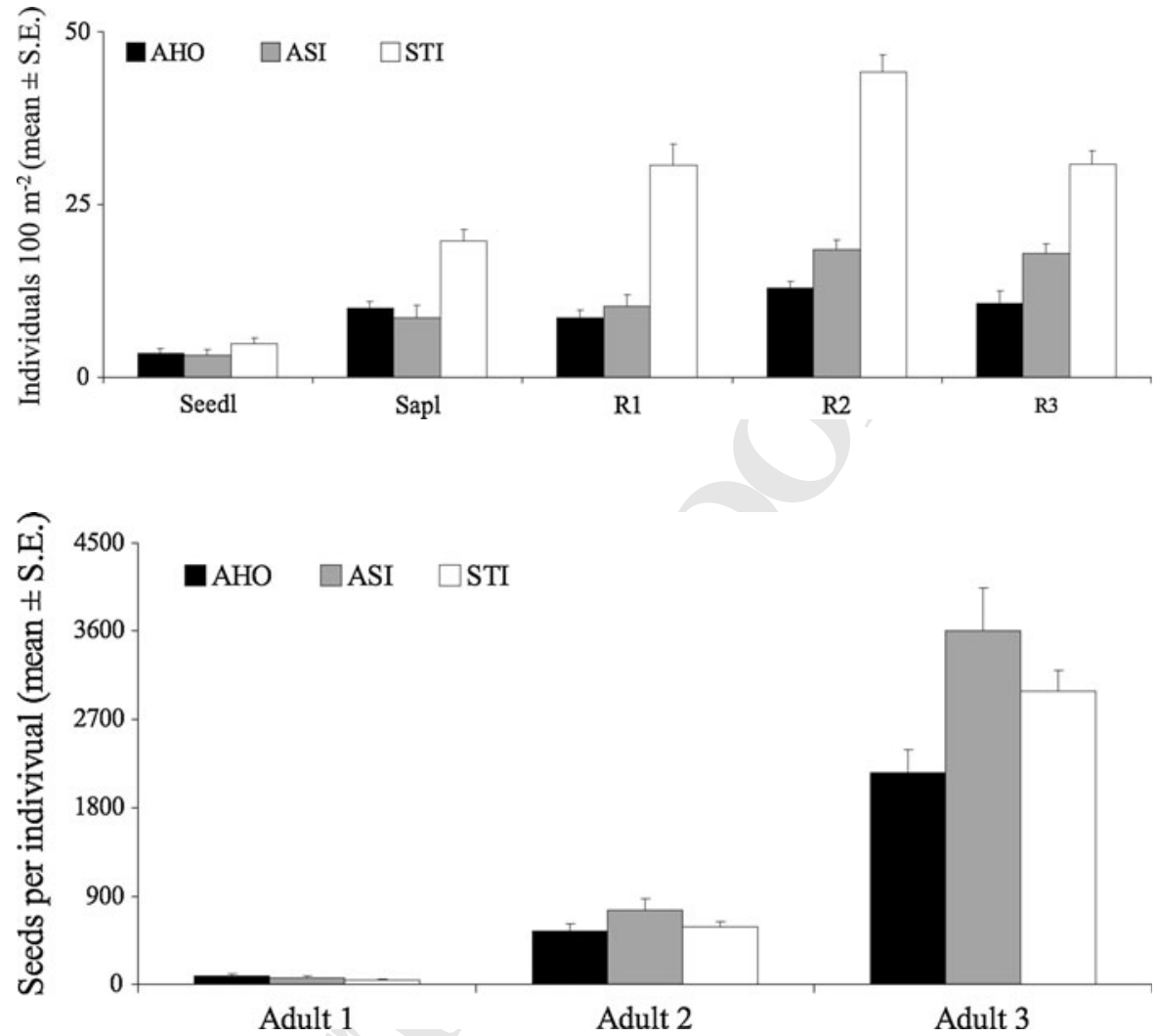

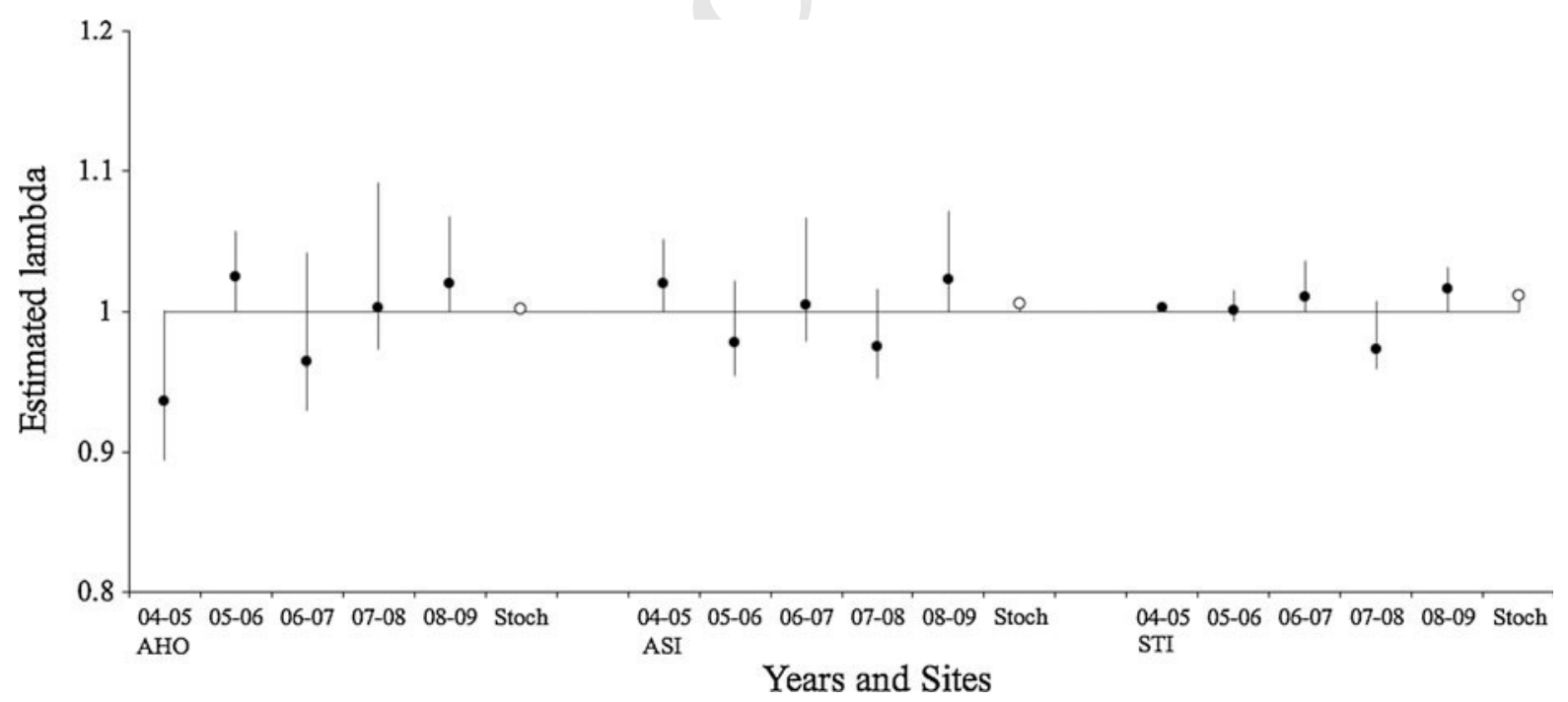

Fig. 3 Stochastic population growth rate $\left(\lambda_{\mathrm{s}}\right)$ in the three study sites. Empty dots correspond to the stochastic population growth rate

394 The effects of herbivores

395 All the three studied populations of $C$. horrida showed

396 signs of damage by herbivores, although the density of damaged individuals was highest in protected populations (ASI: $26.7 \pm 3.2$ damaged individuals $40 \mathrm{~m}^{-2}$; AHO: $16.2 \pm 2.7$ damaged individuals $40 \mathrm{~m}^{-2}$ ) and only occasional in the non-protected population (STI:

\begin{tabular}{|l|lll|}
\hline Journal : Medium 11258 & Dispatch : 16-8-2012 & Pages : 11 \\
& Article No. : 110 & $\square$ LE & $\square$ TYPESET \\
MS Code : VEGE3349 & $\downarrow_{\mathrm{CP}}$ & $\checkmark$ DISK \\
\hline
\end{tabular}


$0.7 \pm 0.5$ damaged individuals $40 \mathrm{~m}^{-2}$ ). Adults suffered the highest incidence of damage, and mechanical damage was the prevalent type. Seedlings and saplings were affected only by MD (Fig. 4).

There were significant differences in the frequency of individuals damaged by herbivores among populations, STI having a significant lower proportion than AHO $(Z=6.796 ; P<0.001)$ and ASI $(Z=8.285$, $P<0.001)$. Such difference was due to the lower proportion of damaged adults in STI respect to AHO $(Z=6.25 ; P<0.001)$ and ASI $(Z=8.43 ; P<0.001)$, whereas the proportion of seedlings and saplings damaged did not differ among populations.

Seed production in fenced plot was significantly higher than in control plots (on average $664.4 \pm$ 200.58 vs $370.6 \pm 83.16$ seeds per individual. $F_{1,6}=$ $11.66, P=0.0142)$. The R3 significantly produced more seeds than the other two reproductive classes $\left(F_{1,6}=62.53, P=0.0001\right)$. The highest contribution to the difference between fenced and control plots was due to class R3, which produced on average $1572.6 \pm$ 74.80 seeds within fenced plots and 717.1 \pm 22.16 seeds in the control plots $\left(F_{2,6}=10.26, P=\right.$ $0.00116)$.

The survival of seedlings $(\mathrm{Z}=-3.303, P<0.001)$ and adults $(\mathrm{Z}=-3.475, P<0.001)$ was significantly lower in control plots than in the exclusions. The presence of herbivores, therefore, significantly increased mortality of some classes in this plant.

None of the ASI population growth rates was significantly different from $\lambda=1$ except 2007-fenced, that was significantly higher than one. Demographic models confirmed that herbivores had a negative effect, given that the stochastic growth rate in control plots was $3.6 \%$ lower than that in fenced plots: $\lambda_{\mathrm{s}}$ control $=$ $0.9490 \quad[95 \% \quad \mathrm{CI}=0.9485-0.9495], \quad \lambda_{\mathrm{s}}$ fenced $=$ 0.9851 [95\% CI =0.9849-0.9854] (Fig. 5). LTRE analysis showed that survival of the largest plants (R3), either in the form of stasis $(48.4 \%)$ or regression $(13.4 \%)$, and growth of the R2 plants (24.6\%), had the

Fig. 4 Percentage of individuals damaged at each study site and for each kind of damage: $A H O$ Alghero, ASI Asinara, STI Stintino, SEEDL seedlings, SAPL saplings, $M D$ mechanical damage, $U N$ unthreading, $B R$ browsing, and $N D$ not damaged
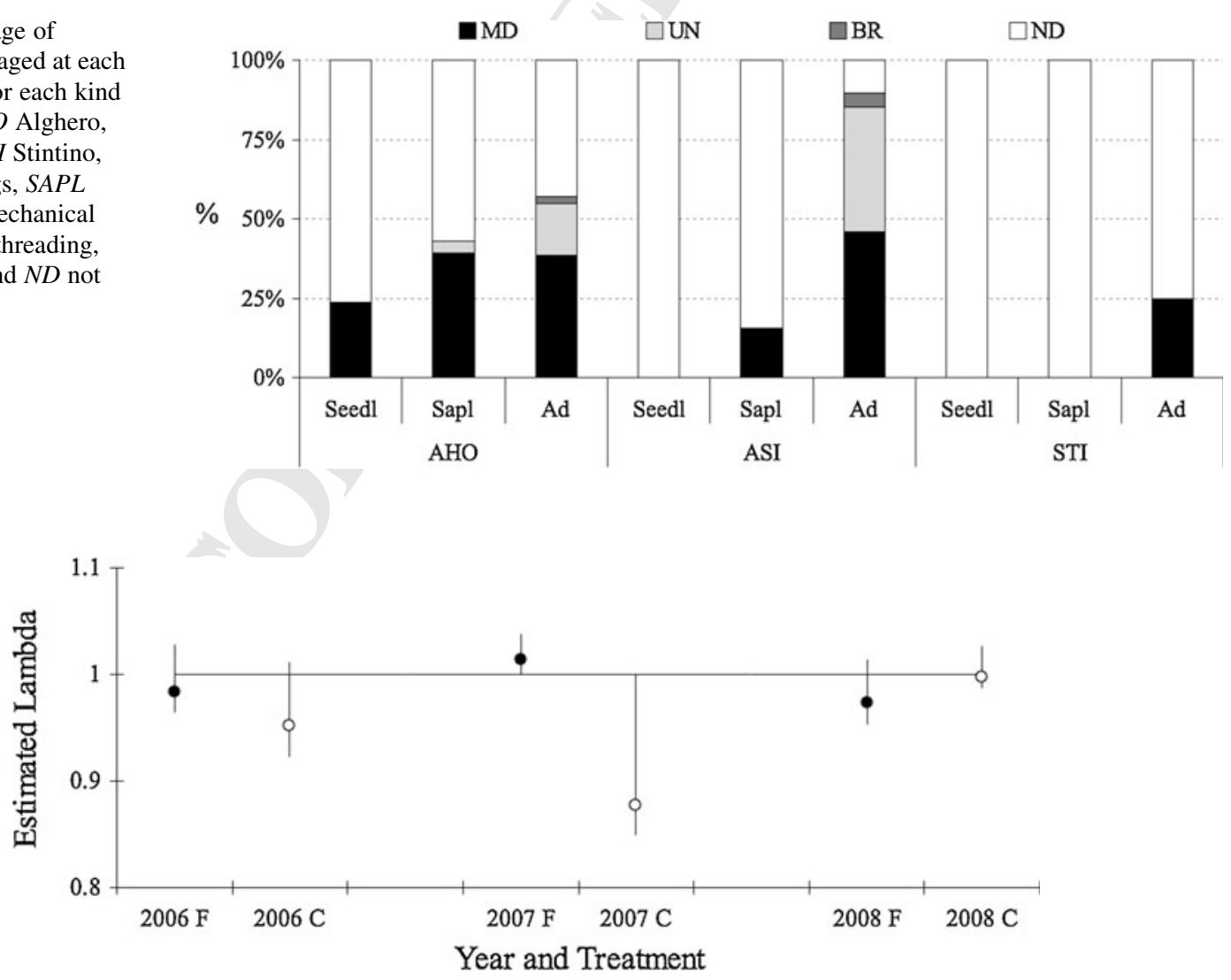

Fig. 5 Deterministic population growth rates and $95 \% \mathrm{CI}$ intervals, of fenced $(F)$ and control $(C)$ plots in ASI. Each dot corresponds to a different combination of treatment (Fenced: black dots; Control: white dots) and transition years (2006, 2007 and 2008)

\begin{tabular}{|l|lll|}
\hline & Journal : Medium 11258 & Dispatch : 16-8-2012 & Pages : 11 \\
Article No. : $\mathbf{1 1 0}$ & $\square \mathrm{LE}$ & $\square$ TYPESET \\
& MS Code : VEGE3349 & $\cup_{\mathrm{CP}}$ & $\searrow$ DISK \\
\hline
\end{tabular}


highest responsibility for enhancing the population growth rate of this species when herbivores are excluded.

\section{Discussion}

This study provided, for the first time, information on the current structure and long-term dynamics of a narrow endemic plant exclusive to an island of the Mediterranean basin, and evaluated the effect of an anthropogenic threat present in two of the three populations analyzed: the introduction of alien ungulates.

Given the environmental and genetic differences among populations we expected a pattern of response variables like ASI $=\mathrm{STI} \neq \mathrm{AHO}$, whereas a pattern like $\mathrm{ASI}=\mathrm{AHO} \neq \mathrm{STI}$ could result from differences in management because of the strong differences in the density of wild ungulates. Our results better fit the second scenario. Although a number of biotic and abiotic factors not considered in this study could be involved in the remarkable among population differences found for $C$. horrida in terms of density and population structure (in particular the higher density of adults and saplings at STI), these differences can at least partially be explained by three of our findings: the higher population growth rate of the nonprotected population, the negative effect of herbivores on the survival of adult plants and on the stochastic long-term population growth rate.

Populations of Centaurea horrida are dominated by adults, who together with the slow growth of the plants (frequency of stasis) suggest that $C$. horrida behaves as a typical long-lived Mediterranean endemic plant: low colonization ability (Colas et al. 1997) and high local persistence (Lavergne et al. 2004; Thompson 2005). Although none of the studied population of this endangered plant seems to be declining, and population sizes are large enough as not to consider the species under extreme concern in the short-term, the detection of threats is of vital importance for narrow endemics, in particular if migration of current populations or the foundation of new populations seems quite unfeasible, as it is the case of old endemics restricted to islands.

Many Mediterranean plants evolved a suite of defences to oppose to natural herbivory (Carmona et al. 2011), and show different defense mechanisms against large herbivores that influence plant palatability (see e.g., Vicari and Bazely 1993) and depend on plant functional traits (Papanikolaou et al. 2011). Although $C$. horrida is naturally defended from herbivores by spines, our study shows that it is affected by browsing and particularly mechanical damage from large herbivores that have been introduced only recently in the island where it occurs.

Studies that have examined the effect of deer herbivory on population growth of perennial plants have found that it has a measurable impact on longterm population dynamics (Knight 2004; McGraw and Furedi 2005). Typically, effects of deer herbivory on understory plants have been examined experimentally using fenced exclosures (e.g., Alverson et al. 1988; Augustine and Frelich 1998; Augustine et al. 1998; Anderson et al. 2001; Townsend and Meyer 2002). These studies show large positive effects of herbivores exclusion on the growth, survival and reproduction of plants. Our results provide similar conclusions. Adult plants of $C$. horrida were the most affected class by ungulates in terms of frequency and survival, and demographic analysis demonstrated that fencing plants to protect them from herbivores enhanced by almost $4 \%$ the long-term population dynamics in the last 5 years. Our analysis also demonstrated that such reduction was due to the probability of stasis and shrinkage (survival) of large adults, the class that most suffered damage by herbivores at that place, and the one releasing more seeds (Farris et al. 2012).

To assess which of the different current management regimes could be better for the persistence of this endangered plant, it is noteworthy that, even if this study demonstrated the detrimental effects of herbivores on the long-term dynamics of $C$. horrida, other previous studies showed that its seed germination totally depends on the presence of bare soil, and therefore, on gaps and other open spaces created and maintained by disturbance (Farris et al. 2009). Furthermore, we have observed that browsing events on $C$. horrida were concentrated mainly during summer months, after pastures were completely grazed and before the germination period. This is congruent with the findings of Miranda et al. (2011), demonstrating that in season-dependent habitats, such as Mediterranean pasturelands, herbivores tend to occupy alternative patches (e.g., Scrubland) when pastures are not productive, i.e., during summer drought.

\begin{tabular}{|l|lll|}
\hline Journal : Medium 11258 & Dispatch : 16-8-2012 & Pages : 11 \\
& Article No. : $\mathbf{1 1 0}$ & $\square$ LE & $\square$ TYPESET \\
& MS Code : VEGE3349 & $\square_{\mathrm{CP}}$ & $\checkmark$ DISK \\
\hline
\end{tabular}


We therefore argue that the complete disappearance of herbivores might not be; however, a desirable option for the conservation of $C$. horrida. In Mediterranean areas, a crucial role in maintaining the spatial heterogeneity of agro-pastoral systems has been traditionally played by sheep livestock, now decreasing or disappearing in many coastal areas, and replaced by mass tourism. The abandonment of historical practices is favouring the spreading of shrub and forest evergreen vegetation (Farris et al. 2009), whereas pastures and dwarf plant communities are dramatically decreasing (Falcucci et al. 2007; Farris et al. 2010). Unlike large ungulates, sheep are less able to browse on spiny plants and cause mechanical injuries to single plant individuals, contemporaneously maintaining open spaces suitable for seeds germination and seedlings establishment, as demonstrated also by some experiments conducted on other plants as Gentiana nivalis L. (Miller et al. 1999). Consequently, a possible management regime for $C$. horrida would be the complete eradication of the most heavy browsers as goats (Campbell and Donlan 2005; Simbaña and Tye 2009), the reduction of the other herbivores (deer, mouflon, horses, and donkeys) to densities compatible to the herb biomass grown each year at each site (Donlan et al. 2002; Miranda et al. 2011), and the maintenance of low densities of controlled sheep (Miller et al. 1999).

Since protected areas are devoted to the conservation of all aspects of biodiversity, some conflicts can emerge when trying to protect animals and plants whose management strategies are in contrast (Gangoso et al. 2006; Fornara and du Toit 2008; White and Goodman 2009). Our study constitutes a clear example on how the protection of alien large mammals (moreover, considered as flag species by protected areas managers) has a negative effect on a singular plant, paradoxically amplified by the lack of any attempt of active conservation of the local plant biodiversity.

Overall, this study has shown that the presence of alien ungulates may have negative effects on the longterm population dynamics of endangered plant species (Bastrenta 1991; Ehrlén 1995; Rydgren et al. 2001) in a protected space designed to preserve overall biodiversity. Although the evaluation of the responses of endangered plant populations to multi-specific assemblages of alien herbivores seems particularly helpful to conservation biologists and land managers, we believe that successful management schemes can only be projected on the basis of future manipulative disentangling species-specific interactions between a protected plant and a single alien herbivore species.

Acknowledgments This study was supported by the Regione Autonoma della Sardegna, LR 7/2007-PO Sardegna FSE 2007-2013, with the Grant No. CRP2_474 for RF and EF, and no. CRP3_188 for SP. MBG also got support from a Spanish National Park project (OAPN, REF. 430/211). We thank the Ente Foreste della Sardegna, the Parco Nazionale dell'Asinara and the Parco Regionale di Porto Conte for the technical aid received.

\section{References}

Abe T, Wada K, Nakagoshi N (2008) Extinction threats of a narrowly endemic shrub, Stachyurus macrocarpus (Stachyuraceae) in the Ogasawara Islands. Pl Ecol 198:169-183

Alverson WS, Waller DM, Solheim SL (1988) Forests too deer-edge effects in northern Wisconsin. Conserv Biol 2:348-358

Anderson RC, Corbett EA, Anderson MR, Corbett GA, Kelley TM (2001) High white-tailed deer density has negative impact on tallgrass prairie forbs. J Torrey Bot Soc 128:381-392

Augustine DJ, Frelich LE (1998) Effects of white-tailed deer on populations of an understory forb in fragmented deciduous forests. Conserv Biol 12:995-1004

Bacchetta G, Farris E, Pontecorvo C (2012) A new method to set conservation priorities in biodiversity hotspots. Plant Biosyst. doi: 10.1080/11263504.2011.642417

Bastrenta B (1991) Effect of sheep grazing on the demography of Anthyllis vulneraria in southern France. J Ecol 79: 275-284

Biondi E, Filigheddu R, Farris E (2001) Il paesaggio vegetale della Nurra. Fitosociologia 38:3-105

Campbell K, Donlan CJ (2005) Feral goat eradications on islands. Conserv Biol 19:1362-1374

Carmona D, Lajeunesse MJ, Johnson MTJ (2011) Plant traits that predict resistance to herbivores. Funct Ecol 25: 358-367

Caswell H (2001) Matrix population models, 2nd edn. Sinauer Associates, Massachusetts

Colas B, Olivieri I, Riba M (1997) Centaurea corymbosa, a cliff-dwelling species tottering on the brink of extinction: a demographic and genetic study. Proc Natl Acad Sci 94: 3471-3476

Conti F, Abbate G, Alessandrini A, Blasi C (eds) (2005) An annotated checklist of the Italian vascular flora. Palombi, Roma

Courchamp F, Chapuis JL, Pascal M (2003) Mammal invaders on islands: impact, control and control impact. Biol Rev 78: 347-383

Cyr H, Pace ML (1993) Magnitude and patterns of herbivory in aquatic and terrestrial ecosystems. Nature 361:148-150

Dolman PM, Waber K (2008) Ecosystem and competition impact of introduced deer. Wildlife Res 35:202-214

Donlan CJ, Tershy BR, Croll DA (2002) Islands and introduced herbivores: conservation action as ecosystem experimentation. J Appl Ecol 39:235-246

\begin{tabular}{|l|lll|} 
Journal : Medium 11258 & Dispatch : 16-8-2012 & Pages : 11 \\
Article No. : 110 & $\square$ LE & $\square$ TYPESET \\
MS Code : VEGE3349 & $\checkmark \mathrm{CP}$ & $\searrow$ DISK \\
\hline
\end{tabular}


Ehrlén J (1995) Demography of the perennial herb Lathyrus vernus. II. herbivory and population-dynamics. J Ecol 83: 297-308

Ehrlén J (2002) Assessing the lifetime consequences of plantanimal interactions for the perennial herb Lathyrus vernus (Fabaceae). Perspect Plant Ecol Evol Syst 5:145-163

Falcucci A, Maiorano L, Boitani L (2007) Changes in land-use/ land-cover patterns in Italy and their implications for biodiversity conservation. Landscape Ecol 22:617-631

Farrington SJ, Muzika RM, Drees D, Knight TM (2009) Interactive effects of harvest and deer herbivory on the population dynamics of American ginseng. Conserv Biol 23: 719-728

Farris E, Filigheddu R (2008) Effects of browsing in relation to vegetation cover on common yew (Taxus baccata L.) recruitment in Mediterranean environments. Plant Ecol 199: 309-318

Farris E, Pisanu S, Ceccherelli G, Filigheddu R (2009) Effects of the management regime on the performance of the endangered Mediterranean Centaurea horrida badarò (Asteraceae). J Nat Conserv 17:15-24

Farris E, Filigheddu R, Deiana P, Farris GA, Garau G (2010) Short-term effects on sheep pastureland due to grazing abandonment in a Western Mediterranean island ecosystem: a multidisciplinary approach. J Nat Conserv 18:258-267

Farris E, Pisanu S, Ceccherelli G, Filigheddu R (2012) Variability at local scales and between habitats in population structure and reproductive traits of the Mediterranean plant Centaurea horrida: implications for management. J Coastal Res 28:193-198

Fenu G, Mattana E, Bacchetta G (2011) Distribution, status and conservation of a critically endangered, extremely narrow endemic: Lamyropsis microcephala (Asteraceae) in Sardinia. Oryx 45:180-186

Fenu G, Mattana E, Bacchetta G (2012) Conservation of endemic insular plants: the genus Ribes L. (Grossulariaceae) in Sardinia. Oryx 46:219-222

Fornara DA, du Toit JT (2008) Community-level interactions between ungulate browsers and woody plants in an African savanna dominated by palatable-spinescent Acacia trees. J Arid Environ 72:534-545

Gangoso L, Donazar JR, Scholz S, Palacios CJ, Hiraldo F (2006) Contradiction in conservation of island ecosystems: plants, introduced herbivores and avian scavenger in the Canary Islands. Biodivers Conserv 15:2231-2248

García MB, Goñi D, Guzmán D (2010) Living at the edge: local versus positional factors in the long-term population dynamics of an endangered orchid. Conserv Biol 24: $1219-1229$

Garzón-Machado V, González-Mancebo JM, PalomaresMartínez A, Acevedo-Rodríguez A, Fernández-Palacios JM, Del-Arco-Aguilar M, Pérez-de-Paz PL (2010) Strong negative effect of alien herbivores on endemic legumes of the Canary pine forest. Biol Conserv 143:2685-2694

Hawkes CV, Sullivan JJ (2001) The impact of herbivory on plants in different resource conditions: a meta-analysis. Ecology 82:2045-2058

Jenkins MA, Webster CR, Rock JH (2007) Effects of chronic herbivory and historic land use on population structure of a forest perennial, Trillium catesbaei. Appl Veg Sci 10:441-450
Knight TM (2004) The effect of herbivory and pollen limitation on a declining population of Trillium grandiflorum. Ecol Appl 14:915-928

Knight TM, Caswell H, Kalisz S (2009) Population growth rate of a common understory herb decreases non-linearly across a gradient of deer herbivory. Forest Ecol Manag 257: 1095-1103

Kose YB, Ocak A, Erkara IP (2010) Centaurea cadmea subsp. pontica subsp. nov. (Asteraceae) from northwest Anatolia. Turkey. Nord J Bot 28:475-478

Kultur S (2010) Centaurea nerimaniae sp. nov. (Asteraceae) from south Anatolia. Turkey. Nord J Bot 28:613-616

Lavergne S, Thompson JD, Garnier E, Debussche M (2004) The biology and ecology of narrow endemic and widespread plants: a comparative study of trait variation in 20 congeneric pairs. Oikos 107:505-518

López-Alvarado J, Sáez L, Filigheddu R, Guardiola M, Susanna A (2011) Centaurea tripontina (Compositae), a new species from the Pre-Pyrenean mountains, Spain. Plant Biosyst. doi: 10.1080/11263504.2011.608736

Mameli G, Filigheddu R, Binelli G, Meloni M (2008) The genetic structure of the remnant populations of Centaurea horrida in Sardinia and associated islands. Ann Bot 101: 633-640

Maron J, Crone E (2006) Herbivory: effects on plant abundance, distribution and population growth. Proc Roy Soc B-Biol Sci 273:2575-2584

Masseti M (2009) Mammals of Mediterranean islands: homogenisation and the loss of biodiversity. Mammalia 73: 169-202

McEachern AK, Thomson DM, Chess KA (2009) Climate alters response of an endemic island plant to removal of invasive herbivores. Ecol Appl 19:1574-1584

McGraw JB, Furedi MA (2005) Deer browsing and population viability of a forest understorey plant. Science 307: 920-922

McPeek MA, Kalisz S (1993) Population sampling and bootstrapping in complex designs: demographic analysis. In: Scheiner SM, Gurevitch J (eds) Design and analysis of ecological experiments. Chapman and Hall, New York, pp 232-252

Médail F, Quézel P (1997) Hot-spots analysis for conservation of plant biodiversity in the Mediterranean Basin. Ann Mo Bot Gard 84:112-127

Médail F, Quézel P (1999) Biodiversity hotspots in the Mediterranean basin: setting global conservation priorities. Conserv Biol 13:1510-1513

Miller GR, Geddes C, Mardon DK (1999) Response of the alpine gentian Gentiana nivalis L. to protection from grazing by sheep. Biol Conserv 87:311-318

Miranda M, Diaz L, Sicilia M, Cristobal I, Cassinello J (2011) Seasonality and edge effect determine herbivory risk according to different plant association models. Plant Biol 13:160-168

Morris WF, Doak DF (2002) Quantitative conservation biology: theory and practice of population viability analysis. Sinauer Associates Inc., USA

Myers N, Mittermeier RA, Mittermeier CG, da Fonseca GAB, Kents J (2000) Biodiversity hotspots for conservation priorities. Nature 403:853-858

$\begin{array}{lll}\text { Journal : Medium 11258 } & \text { Dispatch : } \mathbf{1 6 - 8 - 2 0 1 2} & \text { Pages : 11 } \\ \text { Article No. : } \mathbf{1 1 0} & \square \text { LE } & \square \text { TYPESET } \\ \text { MS Code : VEGE3349 } & \checkmark \text { CP } & \checkmark \text { DISK }\end{array}$


Palombo MR (2009) Biochronology, paleobiogeography and faunal turnover in western Mediterranean Cenozoic mammals. Integr Zool 4:367-386

Papanikolaou AD, Fyllas NM, Mazaris AD, Dimitrakopoulos PG, Kallimanis AS, Pantis JD (2011) Grazing effects on plant functional group diversity in Mediterranean shrublands. Biodiversity Conserv 20:2831-2843

Pisanu S, Filigheddu R, Farris E (2009) The conservation status of an endemic species of northern Sardinia: Centaurea horrida Badarò (Asteraceae). Plant Biosyst 143: 275-282

Rydgren K, de Kroon H, Økland RH, van Groenendael J (2001) Effects of fine-scale disturbances on the demography and population dynamics of the clonal moss Hylocomium splendens. J Ecol 89:395-405

Simbaña W, Tye A (2009) Reproductive biology and responses to threats and protection measures of the total population of a critically endangered galápagos plant, Linum cratericola (Linaceae). Bot J Linn Soc 161:89-102

Spear D, Chown SL (2009) Non-indigenous ungulates as a threat to biodiversity. J Zool 279:1-17
Susanna A, Garcia-Jacas N (2009) The tribe Cardueae. In: Funk VA, Susanna A, Stuessy T, Bayer R (eds) Systematics, evolution and biogeography of the compositae. IAPT, Vienna, pp 293-313

Thompson JD (2005) Plant evolution in the Mediterranean. Oxford University Press, Oxford

Townsend DS, Meyer AD (2002) Rapid recovery of witch hazel (Hamamelis virginiana L.) by sprouting, following release from white-tailed deer (Odocoileus virginianus Zimm.) browsing. Nat Area J 22:290-295

Underwood AJ (1997) Experiments in ecology: their logic design and interpretation using analysis of variance. Cambridge University Press, Cambridge

Vicari M, Bazely DR (1993) Do grasses fight back-the case for antiherbivore defences. Trends Ecol Evol 8:137-141

White AM, Goodman PS (2009) Differences in woody vegetation are unrelated to use by African elephants (Loxodonta africana) in Mkhuze Game Reserve, South Africa. Afr J Ecol 48:215-223

Whittaker RJ, Fernández-Palacios JM (2007) Island biogeography. Oxford University Press, Oxford

\begin{tabular}{|l|lll|}
\hline & Journal : Medium 11258 & Dispatch : 16-8-2012 & Pages : 11 \\
Article No. : $\mathbf{1 1 0}$ & $\square$ LE & $\square$ TYPESET \\
MS Code : VEGE3349 & $V_{\mathrm{CP}}$ & $\checkmark$ DISK \\
\hline
\end{tabular}

